Proceedings of SALT 21: 155-175, 2011

\title{
Implicit Arguments, Paychecks and Variable-Free Semantics*
}

\author{
Walter A. Pedersen \\ McGill University
}

\begin{abstract}
The present paper focuses on a particular class of implicit arguments - what have been termed anaphoric implicit arguments (AIAs) - and presents an account of AIAs in the variable-free (VF) framework introduced in Jacobson 1999, 2000. In particular, it is demonstrated how AIAs allow 'paycheck' (E-type) readings, an observation that goes back to Dowty 1981; it is shown that these readings follow naturally in the VF framework. The VF account is then compared and contrasted with some alternatives, including Condoravdi \& Gawron's (1996) proposal that AIAs pattern with definite descriptions.
\end{abstract}

Keywords: implicit arguments, paycheck pronouns, E-type anaphora, variable-free semantics

\section{Introduction}

The topic of the present study is anaphoric implicit arguments (AIAs), and their incorporation into the variable-free framework proposed in Jacobson 1999, 2000. Special attention is paid to the E-type readings of AIAs first observed in Dowty 1981, and it is demonstrated how such readings follow naturally in a variable-free framework.

The paper is organized as follows: $\S 2$ discusses the data relating to implicit arguments, and in particular to AIAs; $\S 3$ reviews the variable-free framework laid out in Jacobson 1999, 2000; $\$ 4$ shows how anaphoric implicit arguments can be introduced into this framework; $§ 5$ compares the variable-free proposal to various alternatives, including the proposal in Condoravdi \& Gawron 1996 that AIAs pattern with definite descriptions rather than pronouns.

\section{Implicit Arguments}

The term 'implicit argument' is a broad one, and the phenomenon to be discussed here has gone under different names in the literature; this multiplicity of labels reflects both

\footnotetext{
*Thank you to Brendan Gillon, Ed Stabler, Ed Keenan, Jessica Rett, Pauline Jacobson, Chris Barker, Barbara Partee, and the UCLA linguistics department for their helpful comments and suggestions. Thanks also to four anonymous reviewers, and to the audience and organizers of SALT 21.
} 
the varied nature of the phenomenon and the diverse analyses of it that have been proposed. To give a very rough initial characterization, an implicit argument can be said to be present in a sentence when that sentence contains an expression (verb, noun, adjective, adverb, etc.) that expresses an $n$-ary concept but appears with fewer than $n$ overt syntactic arguments. The following sentences of English could all be said to contain verbs with implicit arguments under this definition. ${ }^{1}$

(1) a. The new shoe store opens tomorrow. John can't wait to call _.

b. When John gets hungry, he eats _.

c. After he bathed _, John dressed _ and prepared _ for the meeting.

d. When John and Mary met _ for the first time, they kissed _.

e. This sign cautions_against avalanches. (from Rizzi 1986)

In each of these sentences, the verb preceding the ' - ' expresses a relation between two objects; in each sentence, only the subject syntactic argument position is overtly filled. The 'missing' syntactic object argument in each sentence in (1) is interpreted differently, as the following paraphrases indicate.

(2) a. The new shoe store opens tomorrow. John can't wait to call it.

b. When John gets hungry, he eats something.

c. After he bathed himself, John dressed himself and prepared himself for the meeting.

d. When John and Mary met each other for the first time, they kissed each other.

e. This sign cautions one against avalanches.

(1a) can be said to contain an anaphoric implicit argument (Fillmore's (1986) 'definite null complement ${ }^{2}$ ); (1b) can be said to contain an indefinite implicit argument (Fillmore's 'indefinite null complement'), (1c) contains reflexive implicit arguments, (1d) contains a reciprocal implicit argument and (1e) contains a generic implicit argument. Anaphoric implicit argument phenomena will be the focus of the present paper, as they are the most relevant to issues surrounding a variable-free proposal; although the other types of implicit arguments pose interesting challenges for a theory of grammar, they will be set aside in what follows (see Cote 1996 for discussion on all the various types of implicit arguments in English). ${ }^{3}$

1 Cote (1996: 117) offers three tests for detecting the presence of a null object.

2 Fillmore's labelling of the latter as 'definite' is a bit of a misnomer when the full range of interpretations of this class of implicit arguments is considered. The term 'anaphoric' is also not a perfect label, as the implicit arguments in this class can often receive their value exophorically as well as endophorically.

3 Other phenomona that could potentially fall under the heading of 'implicit argument' include subject-AUX dropping, which is common in informal English (see Cote 1996: §2), and null subjects / objects common in languages such as Chinese, Japanese and many others (see e.g. Huang 1984). 
Implicit Arguments, Paychecks and Variable-Free Semantics

\subsection{Distribution of AIAs}

AIAs can find their value both endophorically (in the surrounding co-text) or exophorically (in the discourse setting). Before considering the full range of possible readings of AIAs, let us turn to their distribution. ${ }^{4}$ All of the AIAs in this section are to be interpreted endophorically, that is, their antecedent can be found (marked with italics) in the preceding textual material.

AIAs can be found in place of overt complements to verbs $(3 a, b)$, relational nouns (3c), relational adjectives $(3 \mathrm{~d})$ and adverbs $(3 \mathrm{e})$.

(3) a. The new shoe store is opening today. John can't wait to call _.

b. The climbers tried all day to reach the summit. John arrived _ first.

c. Mary tolerates John's drinking problem, because John is a friend _.

d. I thought Sue was unusual, but Bill is similar _.

e. The tent looks small, but you can actually stand up inside _.

AIAs are not limited solely to expressions that take overt NP complements; the AIAs in $(3 \mathrm{~b}, \mathrm{c}, \mathrm{d})$, for example, are made overt with the PP complements at the summit, of Mary and to Sue respectively. AIAs can also be found with verbs that take various kinds of clausal complements.

(4) a. John arrived with Sue. Mary noticed

b. I don't know where John went, but I'll find out _.

c. Mary needed someone to fix her car. John volunteered _.

An important point to make regarding implicit complements is that, at least in English, their distribution appears at present to be lexically determined and idiosyncratic (Dowty 1978, Dowty 1981, Fillmore 1986, Ruppenhofer \& Michaelis 2011). Minimal pairs exist which demonstrate the lexical nature of the phenomenon (see e.g. Fillmore 1986, Bach 1994, Ruppenhofer \& Michaelis 2011).

(5) a. The route to the summit was difficult. Only John arrived / *reached.

b. Mary told Billy not to cross the street. Billy disobeyed / *defied.

c. John was cheating on Sue, and Mary found out $/ *$ discovered.

4 Semantic evidence - the full range of pronominal-like interpretative possibilities discussed in $\$ 2.2-$ is used here as the primary diagnostic for the presence of an AIA. See Stanley \& Szabó 2000, Stanley 2000 for arguments for this approach, and Cappelen \& Lepore 2004 for counter-arguments. 
The distribution of AIAs is not limited to complement arguments of open-class expressions. In general, the standard of comparison in a comparative sentence can be provided endophorically or exophorically (cf. Gawron 1995); an example is given in (6).

$$
\text { Mary is tall, but Bill is taller_. }
$$

A contextual component to quantifiers has also been recognized (cf. Westerståhl 1984). This can also be construed as an AIA (cf. von Fintel 1994: §2.2, Stanley \& Szabó 2000).

(7) The hallway was full, and every student _ was talking about Mary. [= every student in the hallway]

Finally, Francez (2010) has argued that the value for the scope set in bare existential sentences is profitably analyzed as having an AIA component.

(8) We had to leave the village. There was no more coffee _. [= there was no more coffee in the village]

Before closing this section, let us point out one final observation concerning AIAs: a sentence may exhibit semantic evidence for the existence of an AIA even when an overt argument is not possible. Adverbs like afterwards and beforehand do not tolerate an overt complement, but show the context-sensitivity characteristic of an AIA (cf. Partee 1989: 269, Gillon 2011). ${ }^{5}$

(9) a. The guests will arrive soon. Let's set the table beforehand (*the guests arrive). b. It's time for your shots. You can have some candy afterwards (*your shots).

\subsection{Readings of Anaphoric Implicit Arguments}

It has been observed that anaphoric implicit arguments may receive many, if not all, of the same readings as overt pronouns; these include exophoric $(10,11 \mathrm{a})$ and endophoric $(10,11 \mathrm{~b})$ readings, quantificationally bound readings $(10,11 \mathrm{c})$ and E-type readings (discussed below) (cf. Dowty 1981, Partee 1989, Condoravdi \& Gawron 1996).

(10) a. WHILE POINTING AT JOHN: $\underline{\mathrm{He}}$ is a famous linguist.

b. John just arrived. He is a famous linguist.

c. Every boy admires his teacher.

5 Partee (1989: 269) provides the noun foreigner as another example of an expression that allows an AIA but not an overt argument. Chris Barker (p.c.) points out that the verb amputate is similar, in that the amputee cannot be mentioned as an overt argument to the verb. 
Implicit Arguments, Paychecks and Variable-Free Semantics

(11) a. WHILE LOOKING AT MY CELLPHONE: I hope John calls_ soon. [= calls me]

b. The new shoe store is opening tomorrow. John can't wait to call _.

c. Every man is worried that his wife will call _ while his mistress is visiting _.

In addition to the exophoric, endophoric and bound readings in (10), it has been observed that pronouns can also receive many 'non-standard' E-type readings; these include 'pronoun of laziness' readings (12a), quantificational subordination readings (12b), modal subordination readings (12c), 'paycheck' readings (12d), and 'donkey' readings $(12 \mathrm{e})$.

(12) a. Every woman brought her dog to the party, but left him outside.

b. Most books have a table of contents. In some, it is at the end.

c. John thinks he will catch $a$ fish, and hopes I will grill it tonight.

d. The wise man gave his paycheck to his wife. The foolish man gave it to his mistress.

e. If a man owns a donkey, he beats it.

All of these readings can be seen as falling in the class of 'E-type' readings, after Evans 1977. It has been suggested that all can be given an E-type analysis like the one in Cooper 1979 (cf. Heim 1990: 139). In the Cooper-style analysis of (12d), shown in (13), the E-type pronoun is analyzed as having two components: a function variable index ' $\mathrm{f} 7$ ' and an entity variable index ' 4 '. Semantically, the function variable component is assigned a value contextually (picking up the salient 'paycheck-of' function), and the entity variable component is bound in the usual way by the foolish man. (For full details in a modern framework, see Heim \& Kratzer 1998: §11.5).

(13) [The wise man] $]_{3}$ gave his 3 paycheck to his wife. [The foolish man] $]_{4}$ gave $\mathrm{it}_{\mathrm{f} 7,4}$ to his mistress.

The examples below show that the same range of E-type readings found in (12) can be found with AIAs (cf. Dowty 1981: 89-90 for the original observations).

(14) a. Every actress left her chauffeur outside at the premiere, and called _ when she was ready to be picked up.

b. The commander ordered every squadron to head to their assigned checkpoint. He was relieved to hear that most squadrons arrived _.

c. John wishes he had a beautiful mistress. But he couldn't visit _ every weekend or his wife would find out.

d. Every good father visits his daughter on her birthday. Bill's a deadbeat dad, so he only calls _.

e. If a farmer has a wife, he should make sure he calls _ when he is traveling. 
Note that such E-type readings of AIAs can be found in all of the environments discussed in $\S 2.1$.

(15) a. GreenCo buries a small amount of its waste matter. SmogCorp buries a much larger amount _.

b. Mary sucks at catching bugs with her hands. But John is surprisingly good _.

c. No tall camper could fit in the tent he brought with him, but every short camper had lots of room inside .

d. Doctors in the village measured the height of every donkey, and compared it with that of its owner. Every donkey was taller _.

e. Each student in the biology class was given a frog. The teacher told each student to inspect five toes _. [i.e. to inspect five toes of his own frog]

f. The policemen checked every student's locker for drugs, even though each student assured him there were no drugs _. [i.e. no drugs in his own locker]

Note also that pronominal objects of clausal complement verbs can have propositional Etype readings (16a, from Jacobson 2000: 135). In the case of verbs (like know) that allow propositional AIAs, these can also have propositional E-type readings (16b).

(16) a. Every foolish man believes that he will win the lottery. No wise man believes it. [i.e. no wise man believes that he himself will win the lottery]

b. Every husband was stealing money from his wife's wallet. Every clever wife knew _. [i.e. knew that own her husband was stealing from her own wallet]

Partee (1989) and Condoravdi \& Gawron (1996) argue that AIAs demonstrate an additional class of E-type readings (though they do not refer to them this way), readings that they claim pronouns do not share. They point to examples such as the following in support of this.

(17) a. Every man who bet on Green Bay won (*it). [i.e. won the bet he made]

b. Every fugitive was caught within a month (*of it). [i.e. of his escape]

c. In all my travels, whenever I have called for a doctor, one has arrived (*there) within an hour. [= i.e. arrived at my location]

We will return to the examples in (17) in $§ 5.3$.

\section{Variable-Free Semantics}

The variable-free (VF) framework, developed in a series of papers by Pauline Jacobson (Jacobson 1999, 2000), is a particular view of syntax and semantics which eschews the use of variables and variable assignments. In this system, syntax and semantics operate 
Implicit Arguments, Paychecks and Variable-Free Semantics

together; a model-theoretic interpretation is provided for each complex expression as it is built in the syntax (cf. Montague 1974). The defining characteristic of the VF framework lies in how it takes ideas from Quine 1966 and from combinatory logic (Curry \& Feys 1958), and attempts to capture natural language phenomena without the use of variables or variable assignments.

Pronouns have traditionally been viewed as the natural language correlate of the logical notion of a variable (Montague 1974, Heim \& Kratzer 1998: §5.3); as such, one of the goals of the VF framework is to account for pronominal phenomena without the use of variables. The VF system of Jacobson 1999 uses a modified version of categorial grammar (one that includes type-shifting combinators) to capture many observations about pronouns. In this system, pronouns denote the identity function over individuals; they are also of a different syntactic category than NPs that do not contain pronouns. A sentence with an unbound pronoun denotes a function from entities to truth-values; this function is then applied to a contextually salient individual. For a full exposition of the framework, the reader is referred to Jacobson 1999. A sample lexicon is shown in (18); note that an expression is a triple of a sound, a syntactic category and a model theoretic meaning.

$\begin{array}{ll}\text { sound } & \text { category } \\ \text { [ love } & (s \backslash n p) \backslash n p \\ \text { [ him } & n p^{n p} \\ \text { [ his mother } & n p^{n p} \\ \text { [ John } & s \backslash(s \backslash n p) \\ \text { [ every boy } & s \backslash(s \backslash n p)\end{array}$

\author{
meaning \\ $\lambda x . \lambda y . y$ loves $x]$ \\ $\lambda x \cdot x]$ \\ $\lambda x$.mother-of- $x]$ \\ $\left.\lambda f_{<\mathrm{e}, \mathrm{t}: f(\mathrm{j})}\right]$ \\ $\left.\lambda f_{<\mathrm{e}, \mathrm{t}>} \cdot\{y: \operatorname{boy}(y)\} \subseteq\{z: f(z)\}\right]$
}

As it stands, the verb call cannot apply to the expression his mother (which contains a pronoun), as the latter is not of the appropriate syntactic type (it is type $\mathrm{np}^{\mathrm{np}}$, and call applies to an expression of type np). In order for the two expressions to be syntactically compatible, call must undergo one of two type-shifting operations: the $\mathbf{g}$ (Geach) rule (actually a family of rules), or the $\mathbf{z}$ (binding) rule. These are shown in (19) and (20).

$$
\begin{aligned}
& \mathbf{g}_{\mathbf{c}}\left(\left[s ; B / A ; f_{<\mathrm{a}, \mathrm{b}>}\right]\right)=\left[s ; B^{C} / A^{C} ; \lambda X_{<\mathrm{c}, \mathrm{a}>} . \lambda Y_{<\mathrm{c}>\cdot} f(X(Y))\right] \\
& \mathbf{z}\left(\left[s ;(\mathrm{s} / \mathrm{np}) / A ; f_{<\mathrm{a},<\mathrm{e}, \mathrm{l}>>}\right]\right)=\left[s ;(\mathrm{s} / \mathrm{np}) / A^{\mathrm{np}} ; \lambda Y_{<\mathrm{e}, \mathrm{a}>} . \lambda x_{<\mathrm{e}>} \cdot f(Y(x))(x)\right]
\end{aligned}
$$

Applying the $\mathbf{g}_{\mathbf{n p}}$ rule to call results in a reading of Every boy loves his mother where the pronoun is free; that is, it results in a sentence that denotes a function from entities to truth-values (note that the $\mathbf{g}_{\text {np }}$ rule must also be applied to the generalized quantifier every boy to 'pass up' the pronoun argument position to the front of the sentence). 
(21)

$$
\begin{aligned}
& \text { Every-boy } \\
& \mathrm{s} \backslash(s \backslash n p) \\
& \mathrm{s}^{\mathrm{np}} \backslash(\mathrm{s} \ln \mathrm{p})^{\mathrm{np}} \\
& \mathrm{s}^{\mathrm{np}} \\
& {[\lambda x .\{y: \operatorname{boy}(y)\} \subseteq\{z: z \text { loves mother-of- } x\}]}
\end{aligned}
$$

Applying the $\mathbf{z}$ rule to call results in a reading where every boy 'binds' his. Note that binding in this system is simply the merging of two argument positions via the $\mathbf{z}$ rule.

(22)

$\begin{array}{ll}\frac{\text { Every-boy }}{\mathrm{s} \backslash(\mathrm{s} \backslash \mathrm{np})} & \frac{\text { loves }}{(\mathrm{s} \backslash \mathrm{np}) \backslash \mathrm{np}} \quad \frac{\text { his mother }}{\mathrm{np}^{\mathrm{np}}} \\ -(\mathrm{s} \backslash \mathrm{np}) \backslash \mathrm{np}^{\mathrm{np}} & \\ -(\mathrm{-} \backslash \mathrm{np}) & \\ -\mathrm{-} & \end{array}$

$\mathrm{T}$ iff $\{y: \operatorname{boy}(y)\} \subseteq\{z: z$ loves mother-of- $z\}$

\subsection{Variable-Free Semantics and E-type Pronouns}

As Jacobson (2000) shows, E-type pronouns follow naturally from the variable-free apparatus; no additional mechanisms are required above what was introduced in the previous section. A sentence with an E-type pronoun is treated as denoting a function from $<\mathrm{e}, \mathrm{e}>$ functions (like the 'mother-of' function) to a truth-value; this function is then applied to a contextually salient $<\mathrm{e}$,e $>$ function. E-type pronouns are derived by applying $\mathbf{g}_{\mathbf{n p}}$ to a regular pronoun; the $\mathbf{z}$ rule is applied to the verb to bind into the E-type pronoun, and $\mathbf{g}_{\mathbf{n}} \mathbf{n p}$ is used to pass up the functional argument. The derivation of Every boy loves her, where her is an E-type pronoun, is shown in (23). ${ }^{6,7}$

6 For the full details of the variable-free account of paycheck pronouns, and a comparison with other approaches, the reader is referred to Jacobson 2000.

7 One might wonder what happens if we apply $\mathbf{g}^{\mathbf{n p}}$ to call instead of $\mathbf{z}$. This will result in a sentence like (i) 
Implicit Arguments, Paychecks and Variable-Free Semantics

(23) Every girl visited her mother. Every boy called her.

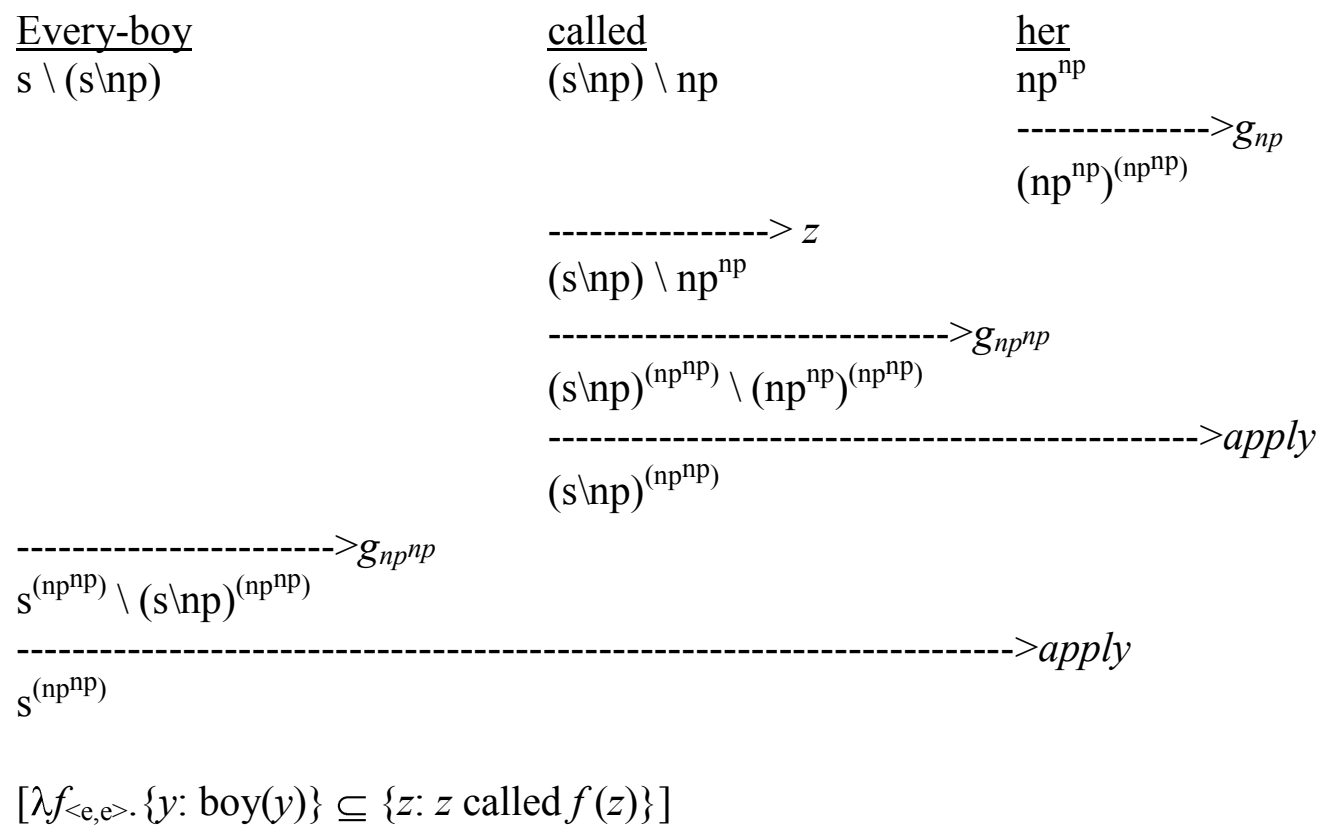

As Jacobson (2000) notes, E-type pronouns are not limited to <e,e $>$ type functional antecedents; their functional antecedents can be (potentially) infinitely complex.

(24) The woman ${ }_{i}$ who made Sears ${ }_{j}$ believe that the bill they $y_{j}$ had sent her ${ }_{i}$ was in the mail was wiser than the woman $_{k}$ who made Filene's $\mathrm{s}_{1}$ believe that it $\mathrm{it}_{\mathrm{f}(\mathrm{k})(\mathrm{l})}$ hadn't been mailed yet.

These higher type E-type readings follow from additional applications of $\mathbf{g}_{\mathbf{n p}}$ to the pronoun, followed by the appropriate uses of the relevant $\mathbf{g}$ and $\mathbf{z}$ rules (cf. Jacobson 2000: §8.3).

(i) $\quad[$ Bill called her ; (snp) (npnp) ; $\lambda f . \lambda x$. Bill called $f(x)]$

In order to complete its meaning, this sentence requires both a salient function and a salient entity to apply it to. Such sentences do in fact seem possible, though perhaps not too easy to come by:

(ii) Every man should talk to [his mother $]_{\mathrm{f}}$ on mother's day. Unfortunately, [John $]_{\mathrm{i}}$ lost his voice. Bill agreed to call her $\mathrm{f}_{\mathrm{f}(\mathrm{i})}$ instead. 
Walter A. Pedersen

\section{Adding Implicit Arguments to VFS}

The addition of AIAs to the variable-free framework is quite straightforward; for simplicity, the account developed here will be limited to verbs that tolerate AIAs. We can view an AIA simply as an argument position of a verb that cannot be filled with a syntactically overt argument; this is to be marked syntactically with the appropriate superscripted category symbol. For example, the intransitive version of call would be of category $(\mathrm{s} / \mathrm{np})^{\mathrm{np}}$; the intransitive version of know would be of category $(\mathrm{s} / \mathrm{np})^{\mathrm{s}}$. It was remarked above that the distribution of AIAs is lexically idiosyncratic; we can assume here, as Dowty $(1978,1981)$ does, that a lexical rule (call it a) derives the syntactically intransitive version of certain verbs. This is illustrated in $(25){ }^{8}$ This lexical rule will be a partial function over the domain of verbs.

$$
\mathbf{a}([s ;(\mathrm{s} \backslash n \mathrm{p}) \backslash A ; f])=\left[s ;(\mathrm{s} \ln \mathrm{p})^{A} ; f\right]
$$

The lexicon will now contain expressions like the following (ignoring intensions for simplicity).

\begin{tabular}{|c|c|c|c|}
\hline $\begin{array}{l}\text { call } \\
\mathbf{a}(\text { call })\end{array}$ & $\begin{array}{l}\text { sound } \\
{[\text { call }} \\
{[\text { call }}\end{array}$ & $\begin{array}{l}\text { category } \\
(s \backslash n p) \backslash n p \\
(s \backslash n p)^{n p}\end{array}$ & $\begin{array}{c}\text { meaning } \\
\lambda x . \lambda y \cdot y \text { called } x] \\
\lambda x . \lambda y \cdot y \text { called } x]\end{array}$ \\
\hline & [ know & & $\lambda t \cdot \lambda y \cdot y$ knows $t$ \\
\hline (know) & [ know & $(s \ln p)^{s}$ & $\lambda t . \lambda y \cdot y$ knows $t$ \\
\hline
\end{tabular}

In what follows, we will abbreviate e.g. a(call) as call 2 . A sentence with an unbound AIA (as in $(11 \mathrm{a}, \mathrm{b})$ ) is derived by simply using the appropriate $\mathbf{g}$ rule on the subject quantifier (and any other intervening expressions) to pass up the AIA argument position. This will result in a sentence that denotes a function (type $<\mathrm{e}, \mathrm{t}>$ or $<\mathrm{t}, \mathrm{t}>$ depending on the verb) rather than a truth-value, i.e. a sentence which is 'looking for' a contextually salient entity or proposition to apply to.

(27) The queen was surprised on her birthday. Every boy called.

$\mathbf{g}_{\text {np }}($ every-boy $)\left(\right.$ call $\left._{2}\right)=$

[every boy called ; $\mathrm{s}^{\mathrm{np}} ; \lambda x \cdot\{y: \operatorname{boy}(y)\} \subseteq\{z: z$ called $\left.x\}\right]$

8 In fact, the proposal presented here can be largely viewed as a variable-free version of the account presented in Dowty 1981. To derive paycheck readings of AIAs, Dowty applies the Cooper 1979 analysis of paycheck pronouns to them, whereas here we apply the variable-free version of the Cooper analysis. See $\S 5.2$ for a comparison. 
Implicit Arguments, Paychecks and Variable-Free Semantics

To derive readings where an AIA in a lower clause is bound by a subject quantifier in a higher clause, $\mathbf{z}$ is applied to the higher verb, thus 'binding' the AIA.'

(28) Every student fears the professor will call.

every-student (z(fear) ( $\mathbf{g}_{\mathbf{n p}}($ the-professor $)\left(\right.$ call $\left.\left.\left._{2}\right)\right)\right)$

To derive E-type readings of AIAs, we need to use $\mathbf{z}$ on the de-transitivized version of the verb (e.g. on call ${ }_{2}$ ). This requires generalizing $\mathbf{z}$ so it can apply to superscripted categories, as shown in (29).

$$
\mathbf{z}(\mathrm{s} / \mathrm{np})^{\mathrm{A}}=(\mathrm{s} / \mathrm{np})^{\left(\mathrm{A}^{\mathrm{np}}\right)}
$$

Using $\mathbf{z}$ on call $\mathrm{l}_{2}$ results in an expression of the same syntactic category and denotation as $\mathbf{g}_{\mathbf{n p}} \mathbf{n p}(\mathbf{z}($ call $))\left(\mathbf{g}_{\mathbf{n p}}(\right.$ her $\left.)\right)$, i.e. as called her in (23).

(30) Every girl visited her mother on mother's day. Every boy called.

$$
\begin{aligned}
& \mathbf{g}_{\mathbf{n}} \mathbf{n p}(\text { every-boy })\left(\mathbf{z}\left(\text { call }_{2}\right)\right)= \\
& {\left[\text { every boy called ; } \mathbf{s}^{\left(\mathrm{np}^{\mathrm{np}}\right)} ; \lambda f_{<\mathrm{e}, \mathrm{e}>} \cdot\{y: \text { boy }(y)\} \subseteq\{z: z \text { loves } f(z)\}\right]}
\end{aligned}
$$

Sentences with propositional AIAs (regular (31) and E-type (32)) are derived in an analogous way, using $\mathbf{g}_{\mathbf{s}}, \mathbf{g}_{\mathbf{s}} \mathbf{n}$ instead of $\mathbf{g}_{\mathbf{n p}}, \mathbf{g}_{\mathbf{n p}} \mathbf{n p}$.

(31) Mary is pretty. And every boy knows.

$\left(\mathbf{g}_{\mathbf{s}}(\right.$ every-boy $\left.)\right)\left(\right.$ know $\left._{2}\right)=$

[every boy knows; s $\mathrm{s}^{\mathrm{s}} ; \lambda t .\{x: \operatorname{boy}(x)\} \subseteq\{x: x$ knows $\left.t\}\right]$

(32) Every boy's sweetheart is planning to leave him. And every boy knows.

$\left(\mathbf{g}_{\mathbf{s}} \mathbf{n p}(\right.$ every-boy $\left.)\right)\left(\mathbf{z}\left(\right.\right.$ know $\left.\left._{2}\right)\right)=$

$\left[\right.$ every boy knows ; $\mathrm{s}^{\left(\mathrm{s}^{\mathrm{np})}\right.} ; \lambda g_{<\mathrm{e}, \mathrm{t}>}\{x: \operatorname{boy}(x)\} \subseteq\{z: z$ knows $\left.g(z)\}\right]$

Just as with E-type pronouns, higher type E-type readings of AIAs can be derived by additional uses of the appropriate $\mathbf{g}$ and $\mathbf{z}$ rules.

9 Note that, in the present account, it is impossible for a subject quantifier to bind an AIA in the same clause. That is, it is impossible for every boy called to mean every boy called himself. This is due to the fact that call $_{2}$ has the same syntactic category and denotation as $\mathbf{g}^{\mathbf{n p}}($ call)(him), and not $\mathbf{z}($ call $)($ him). This is discussed in $\$ 5.1$ below. 
(33) [The foolish criminal $]_{\mathrm{i}}$ told [the good cop $]_{j} \mathrm{~h}_{\mathrm{i}}$ would refuse to speak to the lawyer $[\text { she }]_{j}$ recommended specifically for $[\mathrm{him}]_{\mathrm{i}}$. [The smart criminal $]_{\mathrm{k}}$ told [the bad cop $]_{1}[\text { he }]_{\mathrm{k}}$ would call $\mathrm{f}_{\mathrm{f}(\mathrm{l}) \mathrm{k})}$.

$$
\mathbf{g}_{\mathrm{np}}\left(\mathbf{z}\left(\text { call }_{2}\right)\right)=\left[\text { call } ;\left(\mathrm{s} / \mathrm{np}^{\mathrm{np}}\right)^{\left(\left(\mathrm{np} \mathrm{np}^{\mathrm{np}}\right)\right.} ; \lambda f_{<\mathrm{e},<\mathrm{e}, \mathrm{e}>} \cdot \lambda x . \lambda y \cdot y \text { called } f(x)(y)\right]
$$

The VF account of AIAs can thus capture the free, bound and E-type readings of AIAs.

\section{Comparison with other proposals}

The VF account elucidated above can be seen as having three defining characteristics: (i) it does not require positing, for each AIA, a phonetically null NP or pronoun in the syntax, (ii) it does not make use of indices and variable assignments, and (iii) it predicts that AIAs should behave semantically like pronouns. As these three characteristics are logically independent and should not be conflated, it is worth examining each of them in turn.

\subsection{Null pronouns}

The VF account presented above made use of a (syntactically) de-transitivizing lexical rule along the lines of that in Dowty 1981. Instead of positing such a lexical rule, we could have made use of a phonetically null pronoun like that shown in (34).

$$
\left.\varnothing ; \mathrm{np}^{\mathrm{np}} ; \lambda x \cdot x\right]
$$

Having a null pronoun like that in (34) would allow for all of the same readings of AIAs that the lexical rule account does. However, there is an important difference. In the lexical rule account, an AIA is unable to be bound (in the VF sense) by a subject quantifier in the same clause. This is due to the fact that, for example, call ${ }_{2}$ has the same syntactic category and denotation as $\mathbf{g}_{\mathbf{n p}}$ (call)(him), and not $\mathbf{z}$ (call)(him); there is no operation that could apply to the meaning of call $_{2}$ to merge the subject and object argument slots. An account making use of the pronoun in (34) would allow for such subject binding, as $\mathbf{z}$ could apply to the verb before it combines with the null pronoun.

Whether such binding is desirable or not relates to the question of whether or not AIAs show principle B effects. The data is not clear on this issue at this point, and more empirical work is needed. Cote (1996) remarks that AIAs do seem to demonstrate Principle B effects, but not to the same extent that pronouns do ((35) is adapted from Cote 1996: 127fn). 
Implicit Arguments, Paychecks and Variable-Free Semantics

(35) A: Did Mary get into trouble at work again today?

B: Yes, I saw her today and she said it was terrible. She said that usually her boss doesn't talk to her directly to talk about her problems with other employees...

a. ??but that evening he called to talk about her.

b. \#but that evening he called her to talk about her.

As it stands, not all Principle B effects follow directly from the lexical rule as it is given in $\S 4$; when the subject is a proper name, nothing prevents a free reading of an AIA that then picks up the salient entity denoted by the subject. To capture the full range of Principle B effects, then, the lexical rule in (25) could be modified to remove all reflexive pairs from the denotation of the verb. ${ }^{10}$

$$
\mathbf{a}([s ;(\operatorname{s\backslash np}) \backslash A ; f])=\left[s ;(\operatorname{s} \backslash n p)^{A} ; \lambda x \cdot \lambda y_{y \neq x} . f(x)(y)\right]
$$

Note also that a null pronoun story could be made to capture Principle B effects using the same strategy, i.e. by simply following Jacobson 2007 in requiring irreflexivization to apply to a verb before it can combine with any pronoun, null or otherwise. The difference between the two analyses is that the lexical rule account does not allow subject binding (again, binding in the VF sense) of an AIA to take place; whether this has any empirical consequences or not is left as an open issue. ${ }^{11}$

Leaving aside Principle B, there are more general elegance considerations which can be brought to bear against a null pronoun account of AIAs. Recall that, at least in English, the distribution of AIAs is lexically idiosyncratic. As Partee (1989) points out, a null pronoun story will require listing (using either features, homophonic lexical items or a lexical rule) that certain lexical items and not others can select for a null pronoun; in other words, adding a null pronoun to the lexicon does not escape the need for listing lexically specific information in the grammar. In the VF account presented above, only the lexical rule is needed; the various readings of AIAs follow from the $\mathbf{g}$ and $\mathbf{z}$ rules (which are independently motivated), and nothing extra needs to be added to the lexicon. Furthermore, the awkwardness of a null pronoun account becomes apparent when we consider again expressions which behave semantically as if they have an AIA, but do not allow for any overt realization of that argument. Examples of such expressions were provided in (9); they also include alike, and ago. A null pronoun account would require

10 This follows the account of Principle B in Jacobson 2007.

11 We can note that, at least for the example in (iii), Principle B effects on the AIA (iiib), but not the pronoun (iiia) seem to be completely ameliorated by focus. More empirical work is needed before a generalization can be made, however. See Grodzinsky \& Reinhart 1993, Jacobson 2007 for discussion on focus and Principle B.

(iii) Everyone seems to be calling John to congratulate him on his new baby. a. ?Mary called him, Sue called him, and I think that even HE called him.

b. Mary called, Sue called, and I think that even HE called. 
that expressions such as these be marked as requiring a null pronoun complement (cf. Partee 1989: 269). In the VF account above, such expressions would have only a superscripted version in the lexicon.

To summarize this section, while elegance considerations do seem to favor the VF account presented in $\S 4$ over a null pronoun account, at present the empirical evidence does not seem to rule in favor of one or the other. ${ }^{12}$

\subsection{Indexed open-class expressions (Dowty 1981)}

The present account of AIAs can also be contrasted with the account in Dowty 1981, in that the latter makes use of variables and variable assignments and the former does not. Like the present account, Dowty posits a lexical rule rather than a null pronoun; his rule for de-transitivization derives an indexed version of an open-class (e.g. verb) expression. That is, the de-transitivized version of an expression like call will have a variable index, which can remain free or can be bound in the way it usually is in a variable-full framework. To capture E-type readings, Dowty builds Cooper's (1979) account of E-type pronouns into his de-transitivization rule.

It is difficult to find empirical data pertaining to AIAs that might distinguish the two accounts. In various papers, Jacobson has argued that certain phenomena receive a more empirically adequate analysis in the VF framework than in one with variables and variable binding. These include Principle B effects (Jacobson 2007), as well as focus on paycheck pronouns (Jacobson 2000a) and across-the-board binding (Jacobson 1999: $\S 3.4)$. However, due to the non-overt nature of AIA phenomena, these do not have clear correlates in the AIA domain.

One could argue, however, that once again elegance considerations favor the VF account over the competition. Particular issues arise in the spelling out of a detransitivising rule that converts a non-indexed expression into an indexed one. Dowty's de-transitivising rule is designed to derive expressions such as those in (37) from the transitive version of call; (37a) will allow regular readings of an AIA, (37b) will allow Etype ones (these examples are presented using the notation of Heim \& Kratzer 1998):
a. $\|$ call $\|^{\mathrm{g}}=[\lambda x, x$ called $\mathrm{g}(3)]$
b. $\|$ call $_{\mathrm{f} 7,3} \|^{\mathrm{g}}=[\lambda x . x$ called $(g(f 7)(g(3))]$

One question that arises in the formulation of such a rule is how to determine which index is assigned to the output; that is, why does the output of the rule in (37a) bear the

12 Space precludes discussion of an ellipsis account of AIAs such as that suggested in Mittwoch 1971. But many of the same elegance considerations that argue against a null pronoun account also apply to an ellipsis account; in addition, the existence of exophoric readings of AIAs could be seen to argue against such a proposal. 
Implicit Arguments, Paychecks and Variable-Free Semantics

index 3 and not 1 or 2 ? One can imagine various answers to this question, such as having a different de-transitivizing rule for each possible index (functional or not) or a separate set of indices reserved for the de-transitivization rule, but these details would need to be specified in the formulation. Another elegance issue that arises for an indexing lexical rule is that, depending on its formulation, it may result in a lexicon with a multiplicity (potentially an infinity) of lexical entries for call; there will need to be one for each indexing possibility. Such issues do not arise in the VF account; the de-transitivization rule in $\$ 4$ operates only on the syntactic category of an expression, and no indexing is required as there are no variables or variable assignments.

One final difference to note between the two accounts: in the Dowty account, Etype readings of AIAs result from an idiosyncratic lexical rule applying to certain expressions to produce outputs like (37b); in the variable-free account, E-type readings are derived syntactically using the general $\mathbf{g}$ and $\mathbf{z}$ rules. Thus, E-type readings of AIAs in the VF account are given a syntactic, not a lexical, explanation; only one lexical entry for intransitive call is required to capture all the various readings that an AIA associated with it may exhibit.

\subsection{AIAs and definite descriptions (Condoravdi \& Gawron 1996)}

It was mentioned above that the VF account of AIAs presented here predicts that AIAs should have the same readings as pronouns. However, Partee (1989) and Condoravdi \& Gawron (1996) have both argued that AIAs are somewhat freer in finding a value than pronouns. They point to examples such as (38) as evidence of this.

(38) a. Every man who bet on Green Bay won _.

b. Every fugitive was caught within a month

c. In all my travels, whenever I have called for a doctor, one has arrived _ within an hour.

In the relevant reading of (38a), it is asserted that every man won the bet that he placed; in (38b), it is asserted that every fugitive was caught within a month of his escape; in (38c) it is asserted that a doctor arrived at the location of the speaker, which was changing from time to time. In all of these cases, it is claimed, the antecedent for the AIA is neither fully exophoric nor fully endophoric. Condoravdi \& Gawron argue that the AIAs in (38a-c) have accommodated antecedents; in each case, the value that the AIA receives is entailed by (but not specifically mentioned in) the material preceding the AIA. They claim further that while the sentences in (38) do allow for such readings, analogous ones with pronouns do not.

Every man who bet on Green Bay won it. [\#won the bet he placed] 
Condoravdi \& Gawron take the difference between (38a) and (39) as evidence that AIAs pattern not with pronouns, but with definite descriptions; the latter, they maintain, do allow the same sort of accommodation found in (38). Thus, (40) differs from (39) in that it allows the accommodated reading found in (38a).

(40) Every man who bet on Green Bay won the bet he made.

The claim that AIAs do not pattern with pronouns, if correct, poses a problem for the present analysis. Note that it is not problematic to derive the relevant readings of (38a-c) in the VF analysis. In each case, it could be argued that we have an E-type AIA, and that the preceding material provides the salient $<\mathrm{e}, \mathrm{e}>$ function argument; in (38a) it is the 'bet-of' function, in (38b) it is the 'time-of-escape' function, and in (38c) it is the 'location-of' function. What is problematic is the claim that pronouns do not allow the same sorts of readings.

The empirical situation, however, is more complex and does not appear to warrant such a conclusion at this time, at least not in the case of verbal AIAs. Consider again Condoravdi \& Gawron's example in (38a). The choice of the verb win in this example is problematic; evidence can be found that the implicit argument of win is not, in fact, an anaphoric implicit argument. The sentences in (41) demonstrate that it can receive an indefinite interpretation, with the implicit argument understood as the prize, not the contest; thus (41a) is closer to (41d) than to either (41b) or (41c).

(41) a. Everyone who enters this casino is guaranteed to win.

b. Everyone who enters this casino is guaranteed to win it/them.

c. Everyone who enters this casino is guaranteed to win the bet they make.

d. Everyone who enters this casino is guaranteed to win some money.

One could argue, then, that the perceived similarity between (38a) and (40) is due to Gricean inference, where the listener infers that whatever prize each man in (38a) won resulted from winning the bet he made. Compare the sentences in (41) with the sentences containing eat in (42).

(42) a. Every man who patronized the hot dog stand ate.

b. Every man who patronized the hot dog stand ate it.

c. Every man who patronized the hot dog stand ate the hot dog they bought.

d. Every man who patronized the hot dog stand ate something. 
Implicit Arguments, Paychecks and Variable-Free Semantics

Like (41a), (42a) cannot be paraphrased as (42b). At first glance, (42a) might seem to be paraphrasable as (42c). However, the meaning of (42a) must actually be closer to (42d), as the following sluicing data demonstrates. ${ }^{13}$

(43) a. Every man who patronized the hot dog stand ate, but I don't know what.

b. Every man who patronized the hot dog stand ate something, but I don't know what.

c. \#Every man who patronized the hot dog stand ate the hot dog they bought, but I don't know what.

(43a) does not sound infelicitous, as would be expected if its paraphrase is that shown in (43b) rather than (43c); the perceived inference from (42a) to (42c) must therefore be Gricean. Similarly, sluicing data indicates that the implicit argument of win in (38a) can indeed have an indefinite interpretation; this supports the claim that the connection between (38a) and (40) is a Gricean one.

(44) a. Every man who bet on Green Bay won, but not very much.

b. Every man who bet on Green Bay won some money, but not very much.

c. \#Every man who bet on Green Bay won the bet he made, but not very much.

Such data indicates, at the very least, that win should not be taken as being representive of verbs with AIAs. ${ }^{14}$

Condoravdi \& Gawron's claim that pronouns do not allow the kind of accommodation found in (38a) is also problematic. Consider $(45 \mathrm{a}, \mathrm{b})$, which do allow exactly the sort of accommodation they claim to be present in (38a):

(45) a. Whenever I tip a taxi driver, he puts it in the glove compartment.

b. Every man who bribed a politician watched him put it in his briefcase.

And in cases where a pronoun does allow for accommodated antecedents, the implicit argument does pattern with the pronoun.

(46) a. Hey, newly married men...When you go traveling, make sure to call her!

b. Hey, newly married men... When you go traveling, make sure to call!

Finally, an AIA sometimes resists an accommodation reading, when both a pronoun and

13 The idea of using sluicing as diagnostic for identifying implicit arguments can be found in Thomas 1979, Levin 1982, Levin \& Rappaport 1986, Gillon 2011.

14 The exact status of the IA(s) of win is actually unclear; consider (iv):

(iv) Every man who bet on Green Bay won, but not by very much. 
a definite description allow it; thus, the visitee in (47a) is not naturally interpreted as the donkey owned by the traveler, but (47b) and (47c) do allow for this interpretation (while (47b) is not perfect, there is a definite contrast with (47a)).

(47) When a donkey-owner returns home from his travels...

a. the first thing he does is visit .

b. the first thing he does is visit it.

c. the first thing he does is visit the donkey.

What all of this indicates is that we need a better grasp on the data before we can rule definitively on whether or not AIAs pattern with pronouns; an account which predicts that they do pattern with pronouns, such as the one VF provided here, should not at present be ruled out. ${ }^{15}$

A note on the actual analysis Condoravdi \& Gawron provide for AIAs: as it is presented in a dynamic framework, it can easily handle donkey-anaphoric AIAs like the one in (14e). While their dynamic account can capture such readings, the present VF account can do so only insofar as donkey anaphora can be given an E-type analysis (cf. Heim 1990, Chierchia 1992). ${ }^{16}$

\section{Conclusion}

We have seen in the preceding discussion that AIA phenomena can be given a promising analysis in a variable-free framework. A great number of additional issues and open questions surround AIAs (and implicit arguments in general) as well as E-type anaphora, some of which have been mentioned above. One of the most pressing issues concerning E-type anaphora is whether there is a formal link between an E-type pronoun and its functional antecedent, and if so, what kind. This issue is discussed at length in Heim 1990, Chierchia 1992, Elbourne 2001 and others, and obviously whatever conclusions are drawn on this issue will have direct consequences for an analysis of the E-type readings of AIAs. Let us simply note here that the present account does not posit a formal link between a functional argument of an AIA and its antecedent. If such a link does turn out to be empirically motivated, whether it can be given a variable-free analysis remains to be seen.

15 In sentences like $(37 \mathrm{~b}, \mathrm{c})$, inserting a pronoun does seem to make the relevant reading impossible. It is possible that temporal and locative pronouns/AIAs differ from entity-denoting ones, and may require a different analysis than the one presented here (perhaps one along the lines of Condoravdi \& Gawron 1996). Note though, that an accommodated definite description does not always seem possible either; see (v). At any rate, more empirical work is needed.

(v) Every fugitive escaped within a month of the time. [\#of the time he escaped]

16 Though see Shan 2001 for a variable-free version of dynamic semantics. The present VF account of AIAs can be incorporated straightforwardly into Shan's system with no additional modifications. 
Implicit Arguments, Paychecks and Variable-Free Semantics

\section{References}

Bach, Kent. 1994. Semantic slack: what is said and more. In Savas L. Tsohatzidis (ed.), Foundations of Speech Act Theory: Philosophical and Linguistic Perspectives, 267291. London, England: Routledge.

Cappelen, Herman \& Lepore, Ernie. 2004. Insensitive Semantics. Malden, MA: Blackwell.

Chierchia, Gennaro. 1992. Anaphora and dynamic binding. Linguistics and Philosophy 15(2). 111-183. DOI: 10.1007/BF00635805.

Cooper, Robin. 1979. The interpretation of pronouns. In Frank Heny \& Helmut S. Schnelle (eds.), Syntax and Semantics Vol. 10: Selections from the Third Groningen Round Table, 61-92. New York: Academic Press.

Condoravdi, Cleo \& Gawron, Jean Mark. 1996. The context-dependency of implicit arguments. In Makoto Kanazawa, Christopher Pinon and Henriette De Swart (eds.), Quantifiers, Deduction and Context, 1-32. Stanford, CA: CSLI.

Cote, Sharon Ann. 1996. Null Arguments in English. Ph.D. thesis, University of Pennsylvania.

Curry, Haskell B. \& Feys, Robert. 1958. Combinatory Logic. Amsterdam: NorthHolland.

Dowty, David R. 1978. Governed transformations as lexical rules. Linguistics Inquiry 9(3). 393-426.

Dowty, David R. 1981. Quantification and the lexicon: A Reply to Fodor and Fodor. In Michael Moortgat, Harry van der Hulst and Teun Hoekstra (eds.), The Scope of Lexical Rules, 79-106. Dordrecht: Foris.

Elbourne, Paul. 2001. E-type anaphora as NP-deletion. Natural Language Semantics 9(3), 241-288. DOI: 10.1023/A:1014290323028.

Engdahl, Elisabet. 1986. Constituent Questions. Dordrecht: D. Reidel.

Evans, Gareth. 1977. Pronouns, quantifiers and relative clauses (I). Canadian Journal of Philosophy 7(3), 467-536.

Fillmore, Charles J. 1986. Pragmatically controlled zero anaphora. Berkeley Linguistics Society (BLS) 12, 95-107.

von Fintel, Kai. 1994. Restrictions on Quantifier Domains. Ph.D. thesis, UMass Amherst. Francez, Itamar. 2010. Context dependence and implicit arguments in existentials. Linguistics and Philosophy 33(1), 11-30. DOI: 10.1007/s10988-010-9073-2.

Gawron, Jean Mark. 1995. Comparatives, superlatives and resolution. Linguistics and Philosophy 18(4), 333-380. DOI: 10.1007/BF00984929.

Gillon, Brendan. 2011. Implicit Arguments: A Dilemma for Model-Theoretic Semantics. Ms., McGill University.

Grodzinsky, Yosef \& Reinhart, Tanya. 1993. The innateness of binding and coreference. Linguistic Inquiry 24(1), 69-101. 
Heim, Irene. 1990. E-type pronouns and donkey anaphora. Linguistics and Philosophy 13(2), 137-177. DOI: 10.1007/BF00630732.

Heim, Irene \& Kratzer, Angelika. 1998. Semantics in Generative Grammar. Oxford: Blackwell.

Huang, C.-T. James. 1984. On the distribution of empty pronouns. Linguistic Inquiry 15(4), 531-574.

Jacobson, Pauline. 1999. Towards a variable-free semantics. Linguistics and Philosophy 22(2), 117-185.

Jacobson, Pauline. 2000. Paycheck pronouns, Bach-Peters sentences, and variable-free semantics. Natural Language Semantics 8(2), 77-155. DOI: $0.1023 / \mathrm{A}: 1026517717879$.

Jacobson, Pauline. 2000a. Paychecks and stress. Semantics and Linguistic Theory X (SALT 10).

Jacobson, Pauline. 2007. Direct compositionality and variable-free semantics: the case of "principle B" effects. In Chris Barker and Pauline Jacobson (eds.), Direct Compositionality. Oxford: Oxford University Press.

Levin, Lori. 1982. Sluicing: a lexical interpretation procedure. In Joan Bresnan (ed.), The Mental Representation of Grammatical Relations, 590-654. Cambridge, MA: MIT Press.

Levin, Beth \& Rappaport, Malka. 1984. The formation of adjectival passives. Linguistic Inquiry 17(4), 623-661.

Montague, Richard. 1974. The proper treatment of quantification in ordinary english. In Richmond H. Thomason (ed.), Formal Philosophy: Selected Papers of Richard Montague, 247-270. London: Yale University Press.

Partee, Barbara. 1989. Binding implicit variables in quantified contexts. Chicago Linguistics Society 25, 342-365.

Quine, Willard V. 1966. Variables explained away. American Philosophical Society 104(3), 343-347.

Rizzi, Luigi. 1986. Null objects in italian and the theory of pro. Linguistic Inquiry 17(3), 501-557.

Ruppenhofer, Josef \& Michaelis, Laura A. 2011. Frames predict null-complement interpretations. Conference of the Linguistics Society of Belgium 2009.

Mittwoch, Anita. 1971. Idioms and unspecified np deletion. Linguistic Inquiry 2(2), 255259.

Shan, Chung-chieh. 2001. A variable-free dynamic semantics. Amsterdam Colloquium 13, 204-209.

Stanley, Jason. 2000. Context and logical form. Linguistics and Philosophy 23(4), 391434. DOI: $10.1023 / \mathrm{A}: 1005599312747$.

Stanley, Jason \& Gendler-Szabó, Zoltán. 2000. On quantifier domain restriction. Mind \& Language 15(2-3), 219-261. DOI: 10.1111/1468-0017.00130 
Implicit Arguments, Paychecks and Variable-Free Semantics

Thomas, Andrew L. 1979. Ellipsis: the interplay of sentence structure and context. Lingua 47(1), 43-68. DOI:10.1016/0024-3841(79)90066-4

Westerståhl, Dag. 1984. Determiners and context sets. In Johan van Bentham and Alice ter Meulen (eds.), Generalized Quantifiers in Natural Language, 45-71. Dordrecht: Foris.

Walter A. Pedersen

1085 Docteur-Penfield

McGill University

Montreal, QC H3A 1A7

walter.pedersen@mail.mcgill.ca 